\title{
Um estudo exploratório para avaliar a dificuldade de problemas em ensino de Física utilizando a teoria da carga cognitiva com o auxílio de uma hipermídia
}

Ângelo Mozart Medeiros de Oliveira

angelo.oliveira@bento.ifrs.edu.br 000-0002-7015-2443

stituto Federal do Rio Grande do Su toncalves, Rio Grande do Sul, Brasil

Marco Antonio Moreira moreira@if.ufrgs.br 000-0003-2989-619x

Universidade Federal do Rio Grande do Sul, Porto Alegre, Rio Grande do Sul, Brasi

\section{RESUMO}

No presente trabalho foi realizado um estudo exploratório sobre a resolução de problemas com o auxílio de uma hipermídia. Basicamente, a hipermídia conta com problemas separados em dificuldades estabelecidas teoricamente pela Teoria da Carga Cognitiva (CLT). A CLT surge como uma teoria focada nas técnicas e no desenvolvimento de materiais instrucionais que facilitam a aprendizagem. 0 estudo foi realizado em 35 alunos do 10 ano do ensino médio integrado do IFRS (Instituto Federal do Rio Grande do Sul - Câmpus Ibirubá), que tiveram sua navegação e respostas gravadas em um log, assim como o material produzido por eles durante a realização da tarefa. No que se refere à atribuição de dificuldade a priori aos problemas, os resultados sugerem que a CLT foi consistente. A CLT possibilita identificar o momento em que o aluno não consegue resolver certos tipos de problemas. Como este estudo é exploratório, procuramos contribuir para o levantamento de novas perguntas de pesquisa.
\end{abstract}

PALAVRAS-CHAVE: Resolução de problemas. Carga cognitiva. Hipermídia. 


\section{INTRODUÇÃO}

O objetivo deste estudo é formular as bases para a construção de uma hipermídia adaptativa educacional (H.A.E.) (MAMPADI E MOKOTEDI, 2012; CHEN, 2002; BRUSILOVSKI, 2004; MARTINS ET AL, 2008). Segundo Palazzo (2008) uma hipermídia adaptativa (HA) deve ser: um sistema de hipertexto ou hipermídia, possuir um modelo de usuário e poder adaptar o próprio sistema a partir dos dados do modelo de usuário de forma autônoma. Contudo, embora a pesquisa em ensino mediado por computador na Física seja diversificada, não existem trabalhos que tratam diretamente de ensino de Física e hipermídias adaptativas. Podemos destacar que a razão para isso seja (RETALIS E PAPASALOUROS, 2005):

EAHAs are currently a research topic of particular interest in the broader field of adaptive hypermedia applications and several EAHA systems have been built during the past years... The design and implementation of EAHA are complex, if not overwhelming, tasks. This is due to the fact that it involves people from diverse backgrounds, such as software developers, web application experts, content developers, domain experts, instructional designers, user modeling experts and pedagogues, to name just a few. Moreover, these systems have presentational, behavioral, pedagogical and architectural aspects that need to be taken into account. To make matters worse, most EAHA are designed and developed from scratch, without taking advantage of the experience from previously developed applications, because the latter's design is not codified or documented. As a result, development teams are forced to 're-invent the wheel'.

Assim justificamos a necessidade do presente estudo exploratório, como um primeiro passo para a compreensão do que e como adaptar um conteúdo de Física, uma vez que possuímos pouco conhecimento sobre a interação do aluno com o computador em uma situação bem específica, na qual o computador tenha a capacidade de alterar sua estrutura para atender uma determinada demanda do aluno. Contudo, mesmo não envolvendo o estudo de HA diretamente, vários trabalhos relacionam o padrão de navegação dos alunos a estilos cognitivos e conhecimento prévio.

A hipermídia construída para o estudo exploratório irá conter problemas fechados de Física (conforme PEDUZZI, 1997). Por essa razão, vamos realizar uma revisão sobre a resolução de problemas com o intuito de verificar os principais conceitos e também o conhecimento gerado por essa área de pesquisa muito tradicional e importante no ensino de Física.

Com a finalidade de obter uma boa quantidade de informações sobre o estudo, decidimos realizar uma análise qualitativa dos dados, com alguma análise quantitativa eventual. Veremos que pela natureza da interação do aluno com a hipermídia ficará difícil sustentar uma análise quantitativa confiável, até por que nosso estudo não possui um caráter comprovativo. Deve ficar claro que a hipermídia construída para este estudo não é adaptativa da forma como é discutida por Brusilovsky (2008).

Fiorina et al (2007) atribui os efeitos positivos das hipermídias devido a sua estrutura particular, que permite ao aluno explorá-la de acordo com o seu perfil. Nessa linha de pesquisa encontramos diversos trabalhos com resultados positivos 
(PAPANIKOLAUET AL, 2002; TSENG ET AL, 2008; LIN ET AL, 2005; HUANG E YANG, 2009; ALFONSECA, RODRIGUEZ E PÉREZ, 2007; KELLY E TANGNEY, 2006; CHANG ET AL, 2009; LILLEY, BARKER E BRITTON, 2004). Ainda podemos citar (BABBITT E USNICK APUD MACHADO E SANTOS, 2004):

\begin{abstract}
A hipermídia é um ambiente ideal para auxiliar os estudantes a estabelecerem conexões entre os assuntos estudados, pois possibilita criar facilmente ligações entre conceitos, definições, representações e aplicações relacionadas, ampliadas com a adição de som, movimento e gráficos. A rede de conhecimentos resultante dessas conexões tem o potencial de ser mais rica e forte que o conhecimento obtido com apresentações tradicionais. A hipermídia torna possível o desenvolvimento de sistemas que facultam ao aluno a exploração de um banco de informações conforme suas dúvidas e interesses, optando pelas conexões da forma que desejar. Esse processo permite a construção ativa de conhecimentos, predispondo a descoberta de ideias, temas ou fatos num ambiente de informações e estimulando o desenvolvimento do espírito crítico por requerer participação constante, observação e atribuição de valores.
\end{abstract}

Existem estudos que tentam relacionar o modo de navegação, linear ou nãolinear, do aprendiz com seu estilo cognitivo. Existem resultados positivos em trabalhos que tentaram verificar a relação entre a navegação na hipermídia e o estilo cognitivo em uma situação de aprendizagem (CALCATERRA, ANTONIETTI \& UNDERWOOD, 2005; LEE ET AL, 2005), no entanto, Fiorina et al (2007) não encontraram relação entre o estilo cognitivo e o comportamento na navegação. Paolucci (1998) também não encontrou dados positivos e afirma que a estrutura rica em informação, que uma hipermídia possui, pode levar à distração.

Para o desenvolvimento da hipermídia, vamos utilizar a teoria da carga cognitiva (CLT) desenvolvida principalmente por Sweller (1988). Nela encontramos um bom referencial para qualificar a dificuldade atribuída à determinada questão de Física. Isto irá nos ajudar a ranquear as questões utilizadas na hipermídia.

\title{
RESOLUÇÃO DE PROBLEMAS
}

Frequentemente encontramos na literatura trabalhos que tentam sintetizar a pesquisa em determinada área, na forma de revisão da literatura, assim como os também denominados "estados da arte". Sua importância é inquestionável, pois ajuda os pesquisadores a terem uma ideia geral daquilo que vem sendo pesquisado na área. Sobre a resolução de problemas não é diferente. Assim utilizaremos quando necessário estes trabalhos para elucidar um determinado conceito. Abordaremos também as principais contribuições e também os conceitos derivados da área que servirão de base para a elaboração das questões de nosso estudo exploratório.

Rezende, Ostermann \& Ferraz (2009) em sua revisão em periódicos nacionais compreendidos entre 2000 e 2007, constataram que houve apenas um trabalho com a temática resolução de problemas. Cabral da Costa e Moreira (1996, 1997b) realizaram uma extensa revisão da literatura em resolução de problemas no que se refere à diferença entre novatos e especialistas, aspectos metodológicos e estratégias de resolução de problemas. Dentre os diversos artigos analisados 
podemos destacar algumas conclusões recorrentes, encontradas pelos pesquisadores da área, tais como:

1.Enquanto novatos mencionam cada equação que usam os especialistas usam um procedimento mais geral, compiladamente;

2.Novatos tentam resolver os problemas numa sequência linear sem utilizar conhecimentos auxiliares, enquanto os especialistas tentam resolver por métodos de refinamento se utilizando de conhecimentos auxiliares;

3.Novatos não possuem um conhecimento inter-relacionado, enquanto os especialistas organizam seu conhecimento em blocos coerentes de informação;

4.Novatos consideram aspectos locais e superficiais;

5.Resolver problemas numericamente não significa entendê-los qualitativamente;

Ainda podemos destacar (CABRAL DA COSTA e MOREIRA, 1997a):

\begin{abstract}
...parece que há um consenso que a atividade docente em R. P. deve ser repensada a fim de proporcionar uma participação maior do aluno desde a proposição do problema até a sua solução, enfatizando processos que estimulem o uso do conhecimento conceitual e do procedimental; no combate às concepções intuitivas são recomendados mais tempo do que geralmente se gasta para trabalhar estes conceitos e uma abordagem mais profunda que ao mesmo tempo promova retomada frequente dos mesmos, no sentido de realimentá-los e reavaliá-los; enfatizar processos em R. P. que caracterizem a descoberta científica em um único domínio; a necessidade de prática em R. P. acompanhada da justificativa desta prática ativa a metacognição, principalmente quando permite comparar diferentes processos de R. P. e suas dificuldades
\end{abstract}

Existe uma discussão na literatura sobre a generalidade de procedimentos e habilidades comuns independentemente do tipo de problema proposto, que segundo os autores, "para resolver um problema precisamos prestar atenção nele, recordar, relacionar certos elementos entre si, além de que, na maioria dos problemas estas habilidades devem ser utilizadas numa determinada ordem para que atinjamos a nossa meta" (Cabral da Costa e Moreira, 1997b). Também existe questão da percepção do aluno do que ele está de fato fazendo, e a forma como o professor aborda o assunto, sendo que "a realização das atividades e tarefas em contextos muito definidos e fechados fazem com que os alunos realizem de modo mecânico as atividades, sem envolver-se muito no processo" (Ibid.).

Lucero, Concari e Pozzo (2006) definem problema qualitativo como "aquela situação fechada ou aberta, na qual os dados numéricos são mínimos ou não existem. Aparece como um questionamento que não explicita em forma direta a ordem de calcular o valor de alguma magnitude determinada do fenômeno de estudo, ainda que, às vezes seja necessário recorrer a algum cálculo, que depois de ser interpretado conceitualmente, dará solução ao problema." O que determina o problema qualitativo é a interpretação conceitual das variáveis que eventualmente pode estar acompanhada de expressões matemáticas. Os autores alegam que problemas qualitativos são estratégias eficazes em ensino de Física. Já os problemas quantitativos são aqueles em que para sua resolução necessitam equações e algoritmos numéricos. Pode-se dizer também que são aqueles problemas em que se deve traduzir uma informação de um código a outro diferente por meio de sistemas de representação. 
Segundo Peduzzi (1997) podemos classificar os problemas em ensino de Física em enunciados abertos e fechados. A principal característica de um problema de enunciado aberto é sua falta de dados usuais para a sua resolução tradicional. Conforme o autor (Ibid):

\begin{abstract}
Assim, um enunciado do tipo "Calcule o tempo em que se dará o encontro entre um automóvel e um carro de polícia que se lança em sua perseguição" exemplifica um enunciado aberto, em contraste com um enunciado fechado que, envolvendo situação análoga, apresentaria uma descrição completa da mesma, especificando, para o cálculo do tempo de encontro dos veículos, a separação inicial entre eles, suas respectivas velocidades e os tipos de movimentos. Os problemas sem dados no enunciado obrigam os alunos a fazer hipóteses, a imaginar quais devem ser os parâmetros pertinentes e de que forma intervêm. São as hipóteses que focalizam e orientam a solução. Já a estrutura rígida de um enunciado fechado dá pouca, ou nenhuma, margem para a emissão de hipóteses por parte do solucionador.
\end{abstract}

Um importante aspecto que deve ser constatado é que para a resolução de um problema, tanto aberto quanto fechado, é a necessidade de o aprendiz possuir em sua estrutura cognitiva um conhecimento relevante e estável. Do contrário, ele nem poderia começar a entender a natureza do problema que está tentando resolver (AUSUBEL, NOVAK \&HANESIAN, 1980).

Os estudantes, mesmo aqueles em início da graduação, não são capazes de comparar simultaneamente a velocidade de dois móveis. Um trabalho de extrema relevância para esta tese é o realizado por Andarolo, Bellomonte, SperandeoMineo (1991). Eles desenvolveram um sistema tutor que tenta diagnosticar o entendimento do conceito de velocidade média, tentando criar modelos de usuários. Nele, os alunos observavam simulações de dois móveis, e o objetivo era comparar o diagnóstico humano com aquele realizado pelo tutorial. Os autores detectaram que os alunos novatos ficam presos aos detalhes do movimento, com isso são fortemente influenciados pelas suas respostas a partir de elementos parciais. Assim, eles mudam de ideia em relação as suas respostas mais frequentemente e isso dificulta a tentativa de diferenciar se suas respostas são realmente intuitivas ou se é devido à dificuldade de verbalização na hora de responder uma pergunta por parte do tutor humano. Os autores ainda afirmam que para um sistema tutor existe um pré-requisito: um modelo dinâmico de estudante baseado explicitamente, e com detalhamento adequado, no comportamento do estudante.

Em um estudo mais recente, Walsh, Howard e Bowe (2007) realizaram entrevistas semiestruturadas com 22 alunos de um curso introdutório de Física. $\mathrm{O}$ objetivo era analisar os caminhos que os alunos tomavam ao tentar resolver um conjunto de problemas de cinemática e mecânica. $O$ principal resultado revela que a maioria dos estudantes que iniciam o curso de Física não estão preparados para resolver problemas de forma estratégica e científica. $O$ que continua corroborando com as principais descobertas já levantadas por Cabral da Costa e Moreira (1996, 1997b).

Buteler e Coleoni (2012) trabalharam com a questão da modificação do conhecimento prévio, assim chamado de intuição Física. Por ser um estudo exploratório o autor apenas lança a hipótese sugerindo que existe uma relação mais consistente entre as intuições físicas e matemáticas, atribuindo um papel importante às equações matemáticas. 
Com esta revisão, podemos observar os principais conceitos construídos pela área. Temos em mente que existem dois tipos de problemas quanto aos seus enunciados, que são os problemas abertos e fechados. Também podem ser quantitativos ou qualitativos. As unidades de análises usadas para avaliar se um aluno é dito experiente ou novato é justamente a capacidade que ele tem de gerar hipóteses, utilizar procedimentos gerais para a resolução do problema, utilizar métodos de refinação, usar algum conhecimento auxiliar ou se organiza seu pensamento em blocos coerentes de informação. Ademais, existe grande tendência da pesquisa em resolução de problemas se utilizarem de problemas qualitativos e abertos, seguindo a convicção de que problemas fechados e quantitativos dão pouca margem para a geração de hipóteses.

\section{APRESENTANDO A TEORIA DA CARGA COGNITIVA}

O trabalho de Miller (1956) mostrou que a capacidade de prestar atenção do ser humano é limitada, e isso impõe sérias restrições sobre a quantidade de estímulos que uma pessoa consegue operar. O tamanho dessa restrição foi definido como julgamento absoluto. Mais tarde, o termo memória de trabalho fora utilizado para designar a capacidade humana de armazenar certa quantidade de informação (BADDELEY, 2002), e, desde então, o termo vem sendo utilizado em modelagem computacional da mente.

Devido a diversas evidências experimentais, o termo memória de curto prazo (STM - short-term memory) foi utilizado para contrastar com a memória de longo prazo (LTM - long-term memory). A primeira indica uma forma de armazenamento muito volátil da informação, tal como a tentativa de armazenar uma sequência de números aleatórios. A segunda se refere à capacidade de armazenar uma informação por um longo período de tempo, como o armazenamento do nome da própria pessoa. Ambos os tipos estão contidos dentro da memória de trabalho.

Embora a teoria da carga cognitiva (Cognitive Load Theory - CLT) tenha procedência da década de 70, atribui-se a John Sweller (1988) como o teórico responsável pelos primeiros trabalhos em CLT utilizando o conceito de memória de trabalho, baseado no modelo de Alan D. Baddeley (CHONG, 2005). A teoria é focada simultaneamente na estrutura da informação e na arquitetura cognitiva que permite aos alunos o processamento da informação. É considerada uma teoria psicológica, pois tenta explicar o comportamento que nasce a partir da instrução (MORENO E PARK, 2010). Em CLT, a carga cognitiva é o principal construto de interesse. Sendo também o aprendizado um construto, a CLT foi desenvolvida para explicar os efeitos que os diferentes delineamentos instrucionais têm sobre estes dois construtos.

Dessa forma, a teoria tem permitido a construção de técnicas instrucionais muito eficientes se destacando em relação às outras teorias cognitivas. Isso não significa que as outras teorias tenham falhado ao tentar conciliar a apresentação instrucional e a estrutura cognitiva. Certamente a teoria de Gagné, entre outras, já havia predito que para ocorrer a aprendizagem necessariamente o instrutor deve estruturar as condições internas e externas (ARTINO, 2008).

A CLT trabalha com a hipótese que a memória de trabalho é limitada no que a quantidade de processos que é possível realizar. Por essa razão, em uma situação 
complexa, a tarefa pode facilmente exceder a capacidade cognitiva do aluno. Essa limitação da capacidade de processamento pode explicar o fato de que bons tomadores de decisão se concentram em estratégias que reduzem o processamento cognitivo, através de uma forma heurística de pensamento, quando estão diante de uma grande quantidade de informação para reduzir o esforço cognitivo (NEWELL E SIMON APUD TABATABAI, 1998). Por esse motivo a teoria é muito importante no desenvolvimento de materiais mais eficientes e que ajudem no processo de aprendizagem. Com isso, tomando essa hipótese como verdadeira, podemos alegar que a memória de trabalho tem tamanho limitado, e que se os alunos entrarem em contato com uma grande quantidade de informação, e se sua complexidade for apresentada através de um material que não seja potencialmente significativo, resultará em sobrecarga cognitiva e o possível abandono da tarefa.

\section{PRINCÍPIOS DA CLT}

A CLT se ocupa com a construção de materiais educativos. Essa forma de aprendizagem é chamada pelos teóricos de conhecimento biológico secundário, e não se aplica ao que chamam de conhecimento biológico primário.

O conhecimento biológico primário se refere à capacidade cognitiva que todos nós temos, independente de instrução, que permite adquirir um relevante conhecimento inconsciente, sem qualquer esforço cognitivo e interferência de motivação externa. Um exemplo de conhecimento biológico primário é a aprendizagem da fala; segundo os teóricos, as pessoas normalmente não ficam pensando em como movimentar a língua, coordenar as cordas vocais e controlar a respiração para produzir o som. Nós nos envolvemos nessa complexa tarefa simplesmente ouvindo outras pessoas falarem.

Em contrapartida, o conhecimento biológico secundário é culturalmente dependente. Devemos aplicar certo esforço cognitivo para intencionalmente adquirir certo conhecimento. Para os teóricos, praticamente qualquer forma de instrução consiste em conhecimento secundário.

Diante de uma situação de aprendizagem de novos conteúdos, os estudantes devem manipular as peças da informação na memória de trabalho, antes que possa ser armazenado na memória de longo prazo. Para a CLT, o importante reside em qual o tipo de informação que será processada na memória de curto prazo, impondo assim tipos de carga cognitiva. Para a CLT existem três tipos de fontes de carga cognitiva (ARTINO, 2008): A intrínseca, a alheia ${ }^{1}$ e a relevante ${ }^{2}$.

\section{FONTES DE CARGA COGNITIVA}

\section{A CARGA INTRÍNSECA}

A carga cognitiva intrínseca diz respeito à característica da informação e não à sua apresentação. Sabemos que a forma com que uma informação é apresentada influencia a aprendizagem. No entanto, um fator importante é a complexidade 
tal interação de elementos, a complexidade da instrução aumenta, e esse fenômeno é chamado pelos teóricos de "interatividade de elementos". Então, este fator diz respeito à quantidade de elementos que devem ser processados simultaneamente na memória de trabalho para aprender determinado material instrucional.

A estrutura intrínseca da informação é inalterável. Dessa maneira, o instrutor deverá reduzir a carga intrínseca da informação dividindo ela em estruturas menores quando a carga cognitiva da instrução for muito alta. É possível que um determinado elemento da informação possa ser compreendido isoladamente, tendo uma carga intrínseca baixa por essa razão. No entanto, a partir do momento em que ele interage com outro elemento da informação para formar um novo significado, a carga intrínseca aumentará. Para um indivíduo treinado, dito especialista, a própria interação dos elementos pode ser incorporada em um esquema tornando-a um elemento simples de informação, ocorrendo assim uma redução da carga cognitiva sobre a memória de trabalho. Aqui, esquema significa a combinação de dois ou mais elementos de uma informação.

Um exemplo simples em problemas de Física seria aquele em que a velocidade média $(\mathrm{Vm})$ de um objeto é solicitada conhecendo a distância total percorrida (d) e o tempo gasto no percurso (t). Os elementos da informação são a distância total percorrida, o tempo gasto no percurso e a velocidade média. Poderíamos assumir que isolados, possuem uma determinada carga intrínseca. No entanto, a relação entre eles na forma $V m=d / t$ caracteriza uma interatividade de elementos, aumentando a carga intrínseca. Notamos que, se fosse informada a velocidade média e o tempo gasto no percurso, para calcular a distância total percorrida, teríamos que utilizar a equação em sua forma transformada $\mathrm{d}=\mathrm{Vm} * \mathrm{t}$, aumentando a carga intrínseca. No caso de um indivíduo especialista, a equação da velocidade média será tomada como um simples elemento da informação, reduzindo a carga intrínseca e não sobrecarregando a memória de trabalho, podendo realizar outras operações ainda mais complexas. Dessa maneira, uma vez adquirida a competência de processar os diferentes elementos na memória de trabalho, a interatividade de elementos é alterada. Eles podem ser incorporados em um esquema que pode agir como se fosse um único elemento sendo processado com relativa facilidade na memória de trabalho (POLLOCK ET AL, 2002). Essa mudança de carga intrínseca deve causar a reorganização da memória de trabalho, que segundo a CLT, não há limites. A reorganização é armazenada na LTM, que posteriormente pode ser transferida para a STM em uma determinada situação. Obedecendo ao princípio do limite de mudanças já discutido. Veja que o postulado da carga intrínseca vai ao encontro àquelas conclusões que Cabral da Costa e Moreira (1996, 1997b) haviam encontrado em sua revisão de literatura sobre novatos e especialistas. 


\section{A CARGA ALHEIA}

A carga alheia, ou carga cognitiva ineficaz (ARTINO, 2008), se refere à apresentação da informação. É o resultado de técnicas instrucionais que não solicitam ou facilitam a formação de esquemas por parte do aprendiz, e com isso, é o alvo principal da CLT. Os princípios que caracterizam a cognição humana secundária foram desenvolvidos para tratar primariamente a carga alheia.

Embora também dependa, a carga alheia não está diretamente relacionada à complexidade inerente aos elementos da informação, mas é determinada pela sua apresentação. Ela se torna importante quando a carga intrínseca é alta, ou seja, a quantidade de elementos existente em uma dada situação será um forte indicador de carga alheia. Isto ocorre por que a carga intrínseca e a alheia são aditivas (SWELLER, 2010). O resultado de um material que tem uma forte carga alheia e que ainda conta com grande carga intrínseca é o pouco recurso cognitivo reservado na memória de trabalho para construção dos esquemas.

\section{A CARGA RELEVANTE}

A carga relevante, também conhecida como carga eficaz (ARTINO, 2008), é o resultado dos processos cognitivos que tratam de promover abstrações e combinações de elementos da informação apresentados. Quando a carga intrínseca e alheia é adequada, ou seja, quando existe recurso cognitivo na memória de trabalho suficiente, os alunos podem investir o espaço em processos cognitivos de construção de esquemas. Esses processos podem aumentar consideravelmente a carga cognitiva, e, ao contrário da intrínseca e alheia, a carga relevante contribui para a aprendizagem.

$\mathrm{Na}$ figura 1 vemos a carga cognitiva de um determinado material instrucional. $\mathrm{Em} \mathrm{A)} \mathrm{temos} \mathrm{um} \mathrm{material} \mathrm{que} \mathrm{tem} \mathrm{baixa} \mathrm{carga} \mathrm{intrínseca} \mathrm{e} \mathrm{alheia,} \mathrm{liberando} \mathrm{espaço}$ para a carga relevante. Em B) temos um material que tem carga cognitiva total que extrapola os recursos cognitivos de um aluno, não permitindo nenhum espaço para a carga relevante, tendo como consequência a não construção de esquemas e futuramente a realização de automações.

Um conceito importante associado à carga relevante é o de automação. Um aluno pode formar esquemas a partir de elementos mais simples da informação. Quando o aluno realiza outros processos em que os esquemas são utilizados como elementos, pode liberar mais espaço livre na memória de trabalho, sem haver um esforço consciente para tal. Com a automação, tarefas mais comuns podem ser executadas de forma acurada e fluída. Tendo em vista todas essas assunções teóricas, vemos que a construção de esquemas e automação são as metas principais para o desenvolvimento de materiais instrucionais. 


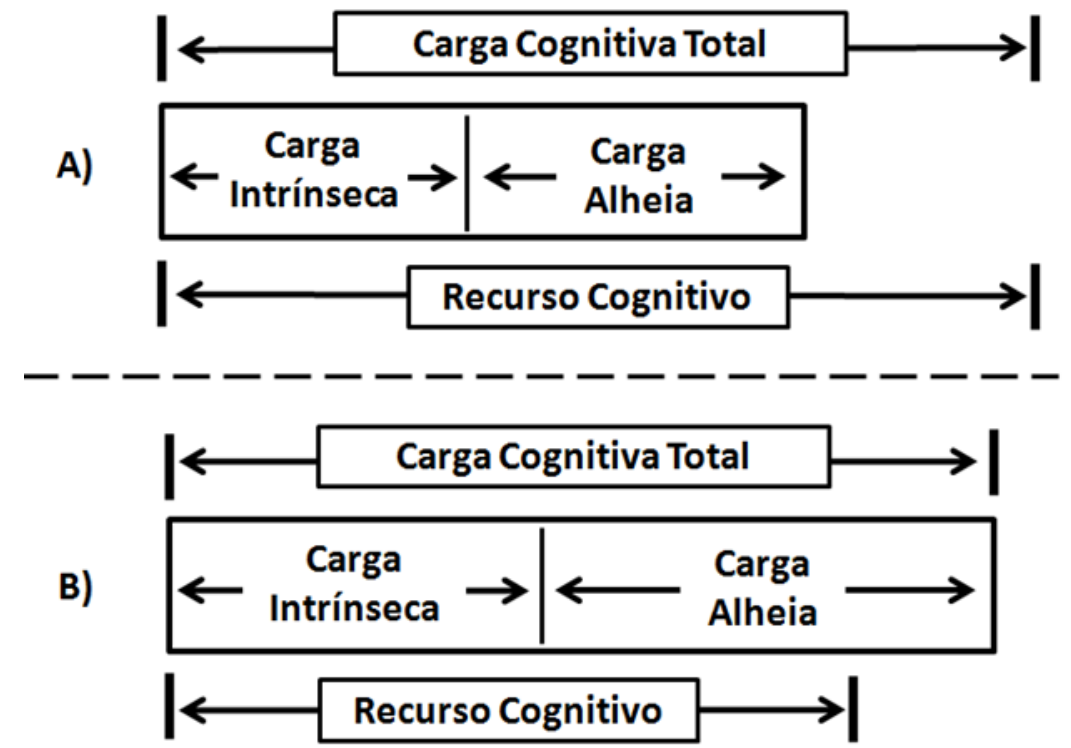

Figura 1: Diagrama que mostra os espaços destinados às cargas cognitivas .

Segundo Pollock, Chandler e Sweller(2002), poderemos ter uma situação em que um novato entra em contato com um material complexo. Se por um lado se quer que um aluno aprenda uma grande quantidade de informações que interagem entre si, ao passo que sabemos que não há condições cognitivas para realizar uma grande quantidade de operações, somos levados a um possível paradoxo. Na verdade, a teoria sugere para esses casos que o material complexo seja quebrado em partes que contenham uma quantidade menor de elementos a cada etapa. Há indícios na literatura que a apresentação de todos os elementos necessários para a compreensão não contribui para compreensão do material.

\section{Efeitos da Carga Cognitiva}

A CLT sugere que devemos ter muita atenção nos efeitos que um material tem sobre os processos cognitivos. Ao desenvolver uma atividade, o instrutor precisa considerar a carga intrínseca que o material possui, a carga relevante necessária para a aprendizagem do material e a carga alheia que não está relacionada à aprendizagem. Com base nos recentes desenvolvimentos da CLT, existem alguns princípios norteadores (efeitos) a serem considerados no momento do desenvolvimento de um material instrucional. Vamos apresentar apenas alguns deles que tratam especificamente de como reduzir a carga alheia, que são os mais importantes para o nosso trabalho. Estes efeitos da carga cognitiva surgem como sugestões para a construção do material instrucional. 
Tabela 1: Alguns efeitos da carga cognitiva e como reduzir a carga alheia (Adaptado de ARTINO, 2008)

\begin{tabular}{|c|c|c|}
\hline Efeito & cão da instr & Carga Alheia \\
\hline $\begin{array}{l}\text { Efeito "Livre } \\
\text { objetivo" (Goal- } \\
\text { freeeffect) }\end{array}$ & $\begin{array}{l}\text { Os problemas convencionais devem } \\
\text { ser substituídos por problemas que } \\
\text { não possuem um objetivo específico. } \\
\text { Tal como um problema aberto. }\end{array}$ & $\begin{array}{l}\text { Reduz a carga alheia ao } \\
\text { diminuir a diferença entre } \\
\text { o estado atual do problema } \\
\text { e sua consequente } \\
\text { resolução. }\end{array}$ \\
\hline $\begin{array}{l}\text { Efeito "Exemplo } \\
\text { resolvido" } \\
\text { (Worked example } \\
\text { effect) }\end{array}$ & $\begin{array}{l}\text { A substituição de exemplos } \\
\text { convencionais por exemplos } \\
\text { resolvidos deve ser cuidadosamente } \\
\text { estudada. }\end{array}$ & $\begin{array}{l}\text { Mesmo que o método } \\
\text { tente reduzir a diferença } \\
\text { entre o estado atual do } \\
\text { problema e sua solução, } \\
\text { pode ocasionar em } \\
\text { aumento desnecessário à } \\
\text { carga alheia. }\end{array}$ \\
\hline $\begin{array}{l}\text { Efeito Modal } \\
\text { (Modality effect) }\end{array}$ & $\begin{array}{l}\text { Substituir problemas textuais ou com } \\
\text { outras fontes visuais de } \\
\text { informação(diagramas) por textos } \\
\text { narrados ou outras fontes que } \\
\text { estimulem diferentes modos. }\end{array}$ & $\begin{array}{l}\text { A redução ocorre devido à } \\
\text { apresentação multimodo } \\
\text { utilizar ambos os } \\
\text { processamentos, visual e } \\
\text { auditivo da memória de }\end{array}$ \\
\hline $\begin{array}{l}\text { Efeito } \\
\text { "Redundância" } \\
\text { (Redundancy } \\
\text { effect) }\end{array}$ & $\begin{array}{l}\text { Substituir diferentes fontes de } \\
\text { informação que explicam o mesmo } \\
\text { conteúdo, por uma única fonte que } \\
\text { pode ser compreendida } \\
\text { isoladamente. }\end{array}$ & $\begin{array}{l}\text { Reduz a carga alheia } \\
\text { causada por } \\
\text { processamentos } \\
\text { desnecessários de } \\
\text { informação redundantes. }\end{array}$ \\
\hline
\end{tabular}

Na tabela 1 vemos uma série de efeitos da carga cognitiva que estão relacionados com a tentativa de redução da carga alheia. Existem outros efeitos para redução da carga intrínseca e relevante. Embora a forma intrínseca que os elementos da informação possuem não pode ser alterada, existe um método (efeito) que visa a sua redução através da apresentação dos elementos separadamente, e então apresentar versões desta interação. Este efeito é chamado de "interação isolada dos elementos", e pode ser usada quando um problema possui uma quantidade muito grande de informações. Os efeitos da carga cognitiva como sugestões de construção de materiais instrucionais devem ser analisados com cuidado, pois a sua utilização não garante a redução da carga cognitiva. Vemos que o efeito "exemplo resolvido" pode ajudar o aprendiz a reconhecer o caminho para a solução de um problema. No entanto, pelo consumo de tempo e recursos cognitivos necessários para a construção do novo esquema, o método pode estar comprometido, pois pode haver o aumento da carga alheia ao invés de sua redução (KALYUGA, 2010). Segundo Kalyuga, Chandler e Sweller (1999) o efeito "redundância" se não tratado corretamente podem prejudicar os alunos especialistas. 
Outra consideração importante é que a redução da carga alheia não está exclusivamente relacionada à quebra da informação nos diferentes canais de percepção (Modo visual, auditivo, etc), mas sim com as técnicas instrucionais utilizadas para facilitar a compreensão de determinado conteúdo. Para isso, diversas técnicas foram desenvolvidas, como pode ser visto na tabela 1 , e note que a maioria delas não se refere aos modos estimulados pela informação.

\section{EXEMPLOS DE APLICAÇÃO DA CLT NA FORMAÇÃO DE PROBLEMAS}

Vamos fazer agora um exercício teórico para analisar a carga cognitiva associada a determinados problemas em Física. Imaginamos que em uma situação de ensino, esses problemas sejam oferecidos aos alunos para resolvê-los com o objetivo de avaliar sua aprendizagem em cinemática. Vamos considerar os exercícios listados na tabela 2.

Não é fácil quantificar a dificuldade de um problema em si mesmo, por essa razão montamos uma escala de dificuldade comparada na primeira coluna da tabela 2, e ao final da análise justificaremos os números. O primeiro problema é bem simples, uma vez que para a sua solução basta aplicar a equação da velocidade média $(\mathrm{Vm}=\mathrm{d} / \mathrm{t})$, pois é conhecida a distância total percorrida e o tempo total de viagem, implicando em uma carga intrínseca baixa. O problema apresenta todos os dados diretamente em seu enunciado, assim podemos afirmar que a carga alheia é baixa, e também por que não há o efeito de "desvio da atenção", pois o problema é direto e o enunciado é curto. Obviamente que nas três situações apresentadas não há ainda a preocupação na redução da carga alheia por efeitos modais.

Já o segundo problema apresenta uma dificuldade maior em relação ao primeiro devido à falta de informações diretas para a solução. Sabemos que muitos problemas que envolvem velocidade média não necessariamente fornecem os dados para a solução, devendo o aprendiz construir um caminho, através de outros meios. Mais ainda, existem problemas que além de não fornecer o tempo gasto na viagem, indicam uma distância percorrida de forma totalmente indireta. Então, pelo fato de que o aluno precisa calcular o tempo total antes de calcular a velocidade média já implica em aumento considerável na carga intrínseca, isto por que é necessário calcular dois intervalos de tempo, um para cada trajetória, e ainda utilizando uma forma diferente da equação da velocidade média $(t=d / V m)$. Se o aluno novato ainda não possui em sua estrutura cognitiva um esquema desta equação, logo, sua forma modificada implica em um aumento da carga intrínseca, pois embora para um especialista tratar-se da mesma equação como um esquema, para o novato isso deve ser verificado. Além disso, existe grande quantidade de informação. Notamos que para diminuir a carga intrínseca poderíamos solicitar ao aluno um passo intermediário, que é calcular o tempo de cada trajetória. Após isso, em outra pergunta solicita-se a velocidade média. Esta quebra da carga intrínseca é conhecida como "interação isolada dos elementos". 
Tabela 2: Exercícios que serão analisados segundo a CLT.

\section{Dificuldade \\ Comparada}

Enunciado

1.

Um automóvel percorre $100 \mathrm{~km}$ em 2 horas. Qual a Fechado e Quantitativo velocidade média do automóvel?

Um automóvel percorre uma distância de 150 km desenvolvendo, nos primeiros $120 \mathrm{~km}$, uma velocidade média de $80 \mathrm{~km} / \mathrm{h}$ e, nos $30 \mathrm{~km}$

2. restantes, uma velocidade média de $60 \mathrm{~km} / \mathrm{h}$. Qual a velocidade média do automóvel no percurso total?

(adaptado de MÁxIMO \& ALVARENGA, 2008).

Calcule o tempo em que se dará o encontro entre um automóvel e um carro de polícia que se lança

3. em sua perseguição.

(Adaptado de PEDUZZI, 1997).
Fechado e Quantitativo

Aberto e Qualitativo

O terceiro problema pode ser considerado como o mais difícil, uma vez que ele não possui nenhuma informação quanto às velocidades, tipos de movimento, distância entre os automóveis. Todas as possíveis variáveis que o problema contenha devem ser hipotéticas. Pelas conclusões apresentados pela nossa revisão da literatura em resolução de problemas, temos razões para acreditar que a geração de hipóteses é boa para avaliar o aprendiz em especialista ou novato, mas fica muito difícil partir para uma metodologia de aprendizagem em ensino de Física com problemas puramente abertos como este. Peduzzi (1997) já nos alerta sobre o erro em impor ao aluno problemas nos quais ele não possui a estrutura cognitiva adequada. Fica evidente que poderíamos escolher um problema aberto um pouco mais simples, mas escolhemos este intencionalmente para demonstrar que a dificuldade de um problema não se resume ao seu tipo (aberto ou fechado, qualitativo ou quantitativo). Diferente dos problemas anteriores que tratavam apenas de um automóvel, este solicita a análise da relação entre dois automóveis. Mesmo que o aprendiz resolva escolher dois movimentos com velocidades constantes em módulo, é grande a relação intrínseca entre as variáveis e conceitos. Dependendo do problema, impor ao aprendiz a geração de hipóteses aumenta tanto a carga alheia (falta de dados) quanto a carga intrínseca (relação entre os automóveis). Pensamos que este problema poderia, em uma determinada metodologia ser oferecido depois de etapas mais simples de resolução de problemas.

Assim, verificamos que para estabelecer a dificuldade dos problemas de Física devemos sempre fazê-lo de forma comparada, ou seja, não há de se falar em um problema difícil a priori. Por essa razão escolhemos indicar, neste conjunto de três problemas, a dificuldade em 1, 2 e 3. Numa situação de vários problemas, a construção da escala de dificuldade deverá ser repensada. 
Quando se constrói novos meios computacionais para a pesquisa em ensino de Física, exige-se do pesquisador um bom domínio do assunto no que diz respeito à linguagem de programação utilizada, sem falar do domínio necessário sobre o próprio tema abordado. Como temos pouca informação sobre o comportamento imediato do programa de computador frente à situação de aprendizagem em Física utilizando uma HA, é necessário realizar um estudo exploratório com o intuito de conhecer melhor o objeto de nossa pesquisa e também melhorar a nossa percepção teórica sobre o assunto. Para a seguinte discussão trouxemos à tona alguns autores que tratam especificamente de metodologias voltadas para as ciências sociais. Mais ainda, visto a escassez de discussão e definição de estudos exploratórios voltados para o ensino de Física, procuramos artigos e trabalhos de pesquisadores de outras áreas que estão mais acostumadas a utilizar este tipo de pesquisa, que são as revistas especializadas em saúde médica.

Analisando as principais revistas de pesquisa em ensino, os estudos exploratórios são pouco utilizados ou assim definidos. Geralmente os trabalhos publicados seguem um padrão: apresentam uma revisão da literatura; um fundamento teórico; estudos realizados com características comprovativas fundamentado na teoria ou prática da literatura; por fim, os resultados. Devido à característica humana da pesquisa em ensino de Física, podem ocorrer imprevistos quando a abordagem do assunto é inovadora, isto é, situações nas quais a teoria, por mais fundamentada que seja, não foi capaz de prever com exatidão os resultados por ser muito ampla, ou até mesmo questões metodológicas tanto qualitativas e quantitativas que poderiam ter sido mais bem planejadas. Com isso, aqueles estudos experimentais que tinham características comprovativas acabam servindo na verdade de base para um próximo estudo. Com o intuito de evitar retrabalhos, os estudos exploratórios deveriam ser um recurso mais utilizado ou assim definido (TRIVIÑOS, 1987):

Os estudos exploratórios permitem ao investigador aumentar sua experiência em torno de determinado problema. O pesquisador parte de uma hipótese e aprofunda seu estudo nos limites de uma realidade específica, buscando antecedentes, maior conhecimentos para, em seguida, planejar uma pesquisa descritiva ou de tipo experimental. Outras vezes, deseja delimitar ou manejar com maior segurança uma teoria cujo enunciado resulta demasiado amplo para os objetivos da pesquisa que tem em mente realizar. Pode ocorrer também que o investigador, baseado numa teoria, precise elaborar um instrumento, uma escala de opinião, por exemplo, que cogita num estudo descritivo que está planejando. Então o pesquisador planeja um estudo exploratório para encontrar os elementos necessários que the permitam, em contato com determinada população, obter os resultados que deseja. Um estudo exploratório, por outro lado, pode servir para levantar possíveis problemas de pesquisa

Ainda podemos citar (GIL, 1999):

As pesquisas exploratórias têm como principal finalidade desenvolver, esclarecer e modificar conceitos e ideias, tendo em vista a formulação de problemas mais precisos ou hipóteses pesquisáveis para estudos posteriores. De todos os tipos de pesquisa, estas são as que apresentam menor rigidez no planejamento. Habitualmente envolvem levantamento bibliográfico e documental, entrevistas não padronizadas e estudos de caso. Procedimentos de amostragem e técnicas quantitativas de coleta de dados não são 
O uso do computador no ensino de Física é um assunto bastante explorado na literatura, com as mais variadas metodologias. HA também são bastante exploradas na literatura da informática. No entanto, HA no ensino de Física são inexistentes. Isso justifica uma pesquisa exploratória, pois não temos informações disponíveis sobre o comportamento dos alunos e da HA frente a uma situação específica de ensino-aprendizagem de Física. E também não temos como formular hipóteses testáveis e operacionalizáveis a princípio.

\section{Construção da Hipermídia}

Agora que possuímos uma visão clara sobre os princípios da CLT, vamos descrever o programa desenvolvido para esta pesquisa. Não entraremos em detalhes técnicos de programação ou de informática, para que nesse momento o foco da discussão fique restrito às suas propriedades educacionais. Também não nos deteremos com questões referentes à segurança da informação neste momento. No entanto, informaremos nos momentos adequados quais os tipos de linguagens utilizadas e suas especificações.

Depois que o aluno realiza o login no sistema, na figura 2 temos a página principal da hipermídia. Na região indicada temos um espaço destinado à apresentação do problema a ser exibido ao aluno. Na mesma figura, ao lado direito observamos o material de consulta. Nele o aluno pode consultar a matéria sempre que achar necessário para resolver um determinado problema. 
Figura 2: Página principal da hipermídia com destaque para o espaço de problemas.

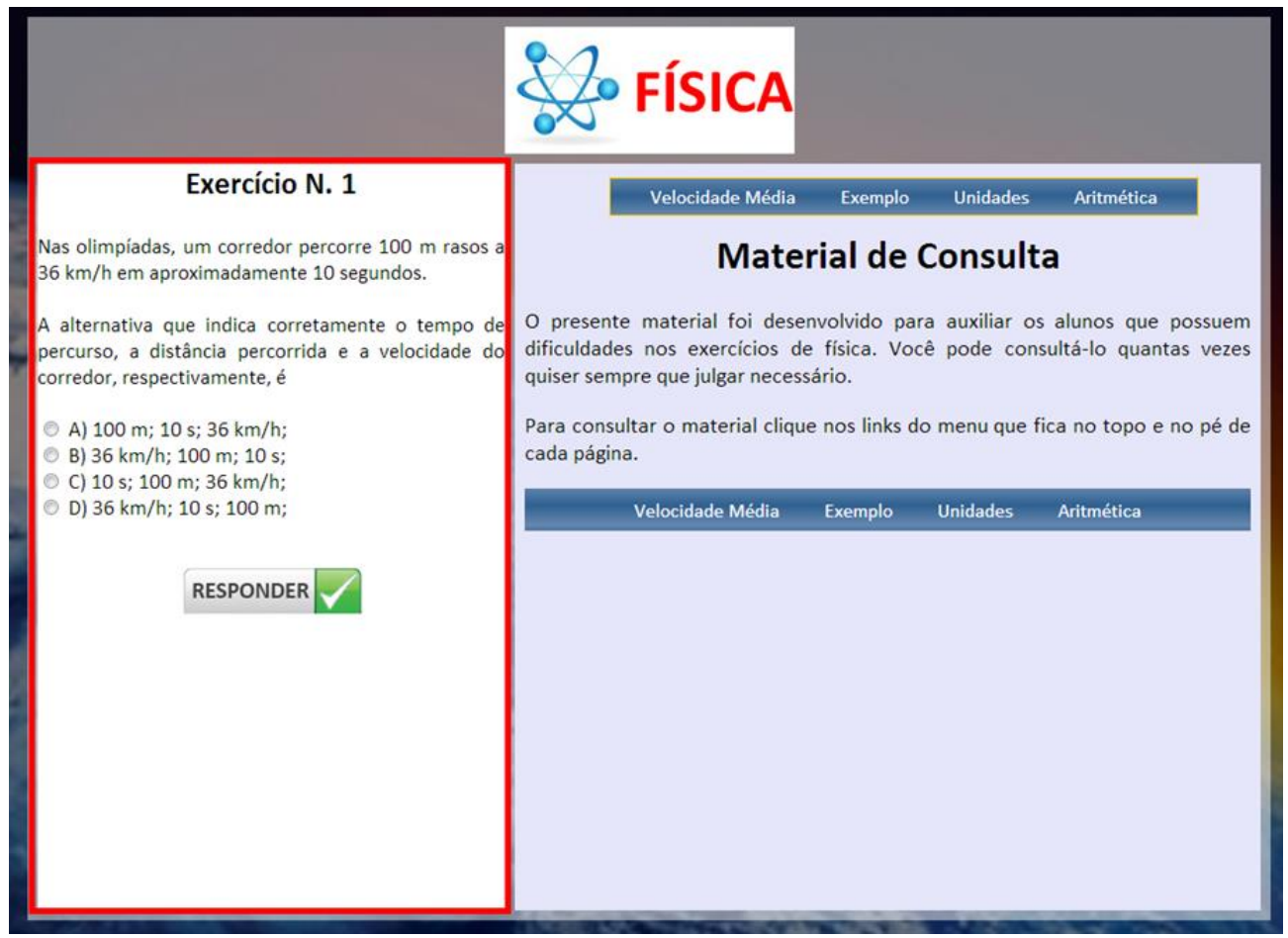

Pensamos que deveria ser desenvolvido um programa voltado para a internet, onde o usuário possa acessá-lo em sua casa, escola ou trabalho, ou seja, uma hipermídia. A rede mundial de computadores pode ser acessada através de um computador que tenha instalado algum navegador, por essa razão buscou-se uma linguagem de programação voltada para a internet. Sendo assim, utilizamos o PHP , pois ele possui a capacidade de se misturar ao HTML, além de ser também uma linguagem de programação opensource mundialmente utilizada. Como o PHP é voltado para a internet e é processado no servidor, não existe nenhuma restrição quanto ao sistema operacional instalado no computador do usuário. Vamos apresentar a hipermídia de uma forma geral.

\section{PÚBLICO ALVO, ELABORAÇÃO DAS QUESTÕES E MATERIAL DE CONSULTA.}

Desenvolvemos a hipermídia com questões sobre velocidade média. A intenção futura é construir um curso inteiro de Física para o ensino médio. Sendo assim, nada mais sensato que começar com essa matéria, sendo um dos primeiros conteúdos abordados (obviamente que antes desse conteúdo teríamos ainda Notação Científica e Algarismos Significativos tal como MÁXIMO E ALVARENGA, 2008; outros ainda trazem a problemática das grandezas escalares e vetoriais antes mesmo do conteúdo de cinemática tal como GASPAR, 2008).

O sistema sorteia as questões a serem apresentadas ao aluno, e aquele exercício já respondido não será apresentado novamente para aquele aluno. A dinâmica de apresentação das questões é semelhante ao realizado por Damando et al (2004), ou seja, se o aluno acerta um problema ele é direcionado para uma questão de maior dificuldade, de acordo com os critérios estabelecidos na tabela 3. Se errar, o aprendiz é direcionado para uma questão de menor dificuldade. A diferença é que a cada resposta fornecida o sistema não recalculará a dificuldade 
do problema e nem reavaliará o perfil do aluno. Entende-se como perfil do aluno os dados referentes ao seu grau de conhecimento do assunto, preferências ou outras características que poderiam ser relevantes para uma adaptação no conteúdo. Em nossa análise dos resultados discutiremos mais sobre a eficiência desse procedimento. Como a adaptação da dificuldade da questão e o conteúdo ainda não são analisados por um módulo de usuário (conforme PALAZZO, 2000), resolvemos chamar essa modificação como "adaptação fraca".

A hipermídia foi aplicada em duas turmas de primeiro ano do ensino médio do curso técnico integrado do Instituto Federal do Rio Grande do Sul - IFRS. Esses alunos frequentam durante a semana apenas dois períodos de Física. No curso integrado, além das disciplinas comuns ao ensino médio, também possuem as disciplinas técnicas.

Participaram da pesquisa 35 alunos que responderam 20 questões sobre velocidade média. Esse número de questões foi escolhido levando em consideração o tempo que os alunos precisam para resolver uma prova de Física. Uma das turmas é a do 10 ano do curso de técnico em informática com 27 alunos. Durante o ano os alunos devem estudar para 15 disciplinas, sendo 4 técnicas. A outra turma que participou da pesquisa é a 10 ano do curso de mecânica que conta com 12 alunos, e da mesma forma que a turma da informática, além das disciplinas do ensino médio, possui 4 técnicas. Percebemos que esses alunos estão submetidos a uma carga cognitiva muito grande, com pouco tempo destinado aos estudos de Física.

A tabela 3 foi construída supondo que o aluno possui uma memória de trabalho fixo, que será dividido entre as cargas cognitivas intrínseca, alheia e relevante. Resolvemos assim chamar essa suposição de "suposição fixa-linear". Ela foi construída tomando como base os exercícios característicos do conteúdo abordado (conforme SAMPAIO E CALÇADA, 2005; MÁXIMO E ALVARENGA, 2008; PARANÁ, 2005; GASPAR, 2008). Nós observamos algumas destas características e avaliamos a carga cognitiva associada. Deve ficar claro que a tabela 3 se refere exclusivamente ao conteúdo de velocidade média. Por exemplo, entendemos que se o problema impõe ao aluno utilizar o conceito ou a equação com os dados fornecidos explicitamente pelo problema, teremos uma diminuição da carga intrínseca, um aumento da carga relevante (o que é bom) e a carga alheia não possuirá influência (neutro).

O material de consulta para os alunos durante a realização dos problemas foi preparado com base em alguns livros de Física para o ensino médio. Como o conteúdo trata de velocidade média, construímos um espaço onde o aluno poderia consultar o conceito de velocidade média, um exemplo característico do conteúdo de forma simples, outro espaço onde o aluno poderia consultar a unidades de medida e por fim um espaço com ajuda com operações elementares, conforme pode ser visto no menu superior na figura 2.

Seguindo essa definição veremos que a partir de determinado nível de dificuldade os problemas poderão exigir um recurso cognitivo maior do que aquele disponível ao aluno. Isso significa que para o aluno resolver o problema, ele dependerá da construção de automações e de esquemas, do contrário, não conseguirá avançar a partir de determinado nível. Escolhemos 10 questões para compor cada nível de dificuldade, para que um determinado exercício não se repita. Os problemas de cada nível solicitam a mesma operação da equação da 
velocidade média, embora os enunciados sejam diferentes. As questões de Física são fechadas e quantitativas, para facilitar a coleta de dados pelo computador, assim como avaliar a correção da resposta.

Tabela 3: Aumento da carga cognitiva de acordo com a característica do problema.

\begin{tabular}{|c|c|c|c|}
\hline \multirow{2}{*}{ Ação característica do aluno/Característica do problema } & \multicolumn{3}{|c|}{ Tipo de Carga Cognitiva } \\
\hline & Intrínseca & Alheia & Relevante \\
\hline $\begin{array}{l}\text { 1) Utilizar o conceito ou equação com os dados fornecidos } \\
\text { explicitamente pelo problema; } \\
\text { 2) Promove a realização de contas independentes; }\end{array}$ & Diminui & Neutro & Aumenta \\
\hline $\begin{array}{l}\text { 3) Para a solução do problema é necessário combinar dois ou mais } \\
\text { resultados intermediários ou equaçães (cada combinação); } \\
\text { 4) Combinar com os dados do problema um procedimento } \\
\text { matemático ou conceitual que não pertence exclusivamente ao } \\
\text { conteúdo; } \\
\text { 5) Para a solução do problema o aprendiz deve manipular a } \\
\text { equação para isolar um dos termos que não o definido pelo conceito } \\
\text { ou equação (cada manipulação). } \\
\text { 6) O problema não fornece diretamente cada informação } \\
\text { necessária para a sua resolução. } \\
\text { 7) O problema fornece grandezas com unidades que devem ser } \\
\text { transformadas. }\end{array}$ & Aumenta & Aumenta & Diminui \\
\hline Os problemas se apresentam contextualizados. & Neutro & Diminui & Aumenta \\
\hline $\begin{array}{l}\text { 9) o problema possui um enunciado muito longo ou mal } \\
\text { contextualizado. }\end{array}$ & Neutro & Aumenta & Diminui \\
\hline
\end{tabular}

Mais uma vez ressaltamos que a dificuldade atribuída é determinada pela expectativa que o aprendiz execute as ações que cada problema sugere de acordo com a tabela 3 . Apenas da análise do material recolhido que poderemos ver se isto realmente acontece ou não. A escolha por problemas fechados e quantitativos se deve a facilidade de verificar computacionalmente se a resposta do aluno está correta ou não. Vamos usar a tabela 3 para sugerir uma dificuldade a priori aos problemas que apresentam essas características, ou ainda, as apresentam de forma acumulativa. Na tabela 4 podemos ver os enunciados dos problemas representativos de cada nível de dificuldade atribuída. Os problemas de dificuldade 1 são os de entrada e servem de parâmetro para os problemas de dificuldade 2. Logo, como um exemplo, a tabela 4 deve ser lida da seguinte maneira: os problemas de dificuldade 2 em relação aos de dificuldade 1 aumentam a carga Intrínseca e Alheia, diminuindo a carga relevante. Pelos motivos apresentados, este aumento de carga cognitiva aumenta a dificuldade da questão.

Com isso, a hipermídia irá apresentar ao aluno problemas de diferentes dificuldades de acordo com o acerto ou o erro. Se o aluno acertar um problema ele é direcionado a resolver um problema de dificuldade um pouco superior. Se errar, será direcionado a um problema de dificuldade um pouco inferior, da forma como é apresentado na tabela 4. Assim, se o aluno responde corretamente o problema de dificuldade 3, será apresentado para ele um problema de dificuldade 4, mas se ele errar, passará para um de dificuldade 2. Todos os alunos começam respondendo o problema de dificuldade 1 .

Tabela 4: Problema característico do grupo de dificuldade e a carga cognitiva atribuída. 


\begin{tabular}{|c|c|c|c|c|}
\hline \multirow{2}{*}{ Dificuldade } & \multirow{2}{*}{ Problema } & \multicolumn{3}{|c|}{ Tipo de Carga Cognitiva } \\
\hline & & Intrínseca & Alheia & Relevant \\
\hline 1 & $\begin{array}{l}\text { Um automóvel a } 40 \mathrm{~km} / \mathrm{h} \text { consegue } \\
\text { percorrer uma estrada de } 5 \mathrm{~km} \text { em } \\
\text { aproximadamente } 7,5 \text { minutos. A } \\
\text { alternativa que indica corretamente a } \\
\text { velocidade, o tempo de viagem e a } \\
\text { distância percorrida pelo automóvel, } \\
\text { respectivamente, é: }\end{array}$ & - & - & - \\
\hline 2 & $\begin{array}{l}\text { Quanto vale } 30 \mathrm{~m} / \mathrm{s} \mathrm{em} \mathrm{km} / \mathrm{h} \text {, e } 3 \mathrm{~h} \text { em } \\
\text { minutos, respectivamente? }\end{array}$ & Aumenta & Aumenta & Diminui \\
\hline 3 & $\begin{array}{l}\text { Nas olimpiadas, um corredor percorre } 200 \\
\text { m rasos aproximadamente } 20 \text { segundos. } \\
\text { Qual a velocidade média do corredor? }\end{array}$ & Aumenta & Neutro & Diminui \\
\hline 4 & $\begin{array}{l}\text { Qual será a distância percorrida de um } \\
\text { automóvel com uma velocidade média de } \\
20 \mathrm{~m} / \mathrm{s} \text { em } 15 \text { segundos? }\end{array}$ & Aumenta & Aumenta & Diminui \\
\hline 5 & $\begin{array}{l}\text { Um leopardo alcança uma presa } \\
\text { percorrendo } 69 \text { metros com uma } \\
\text { velocidade média de } 13 \mathrm{~m} / \mathrm{s} \text {. Qual o } \\
\text { tempo que o leopardo levou para alcançar } \\
\text { a presa? }\end{array}$ & Aumenta & Aumenta & Diminui \\
\hline 6 & $\begin{array}{l}\text { Um ônibus faz um percurso de } 3 \mathrm{~km} \text { em } \\
1,5 \text { minutos em uma estrada. Qual a } \\
\text { velocidade média do ônibus durante este } \\
\text { percurso? }\end{array}$ & Aumenta & Aumenta & Diminui \\
\hline 7 & $\begin{array}{l}\text { Qual será a distância percorrida de um } \\
\text { automóvel com uma velocidade média de } \\
72 \mathrm{~km} / \mathrm{h} \text { em } 10 \text { segundos? }\end{array}$ & Aumenta & Aumenta & Diminui \\
\hline 8 & $\begin{array}{l}\text { Se um atleta percorrer uma prova de } \\
\text { atletismo de } 1,8 \mathrm{~km} \text { com uma velocidade } \\
\text { média de } 5 \mathrm{~m} / \mathrm{s} \text {, qual será o tempo } \\
\text { alcançado por este atleta? }\end{array}$ & Aumenta & Aumenta & Diminui \\
\hline 9 & $\begin{array}{l}\text { Um trem de } 50 \text { metros de comprimento, } \\
\text { com velocidade de } 72 \mathrm{~km} / \mathrm{h} \text {, atravessa um } \\
\text { túnel de } 100 \text { metros de comprimento. } 0 \\
\text { tempo de travessia será de: }\end{array}$ & Aumenta & Aumenta & Diminui \\
\hline 10 & $\begin{array}{l}\text { Um observador O, situado em C, vê passar } \\
\text { uma carreta M dotada de velocidade } \\
\text { constante } 17 \mathrm{~m} / \mathrm{s} ; 4,2 \text { segundos depois } \\
\text { ouve o choque da carreta contra o } \\
\text { obstáculo AB. Sendo de } 340 \mathrm{~m} / \mathrm{s} \text { a } \\
\text { velocidade de propagação do som no ar, } \\
\text { qual a distância que separa o observador } \\
\text { do obstáculo. Considere despreziveis as } \\
\text { dimensões da carreta. }\end{array}$ & Aumenta & Aumenta & Diminui \\
\hline
\end{tabular}

\section{ANÁLISE DE DESEMPENHO}

Aos alunos foram atribuídos números de identificação. Ao todo 35 alunos foram testados e responderam 20 questões (exceto os alunos 39 e 52). Para isso utilizaram caneta e papel para realizar os cálculos, que entregaram ao final da atividade. Vamos começar fazendo uma análise global dos resultados obtidos até agora.

A média de acertos dos alunos foi de 13,23 questões e o de erros foi 6,46 questões. Contudo, como as questões não foram as mesmas para cada aluno devido à natureza da adaptação fraca, seria incorreto classificar os alunos em termos de acertos e erros comparados com o geral neste momento. Isso 
dependerá de uma futura construção matemática estatística adequada. Mas nesse momento podemos argumentar que, dentro das limitações que cada aluno apresentou neste teste, eles responderam corretamente 13 questões e erraram seis questões.

Na figura 3 vemos gráficos que demonstram o desempenho analítico de alguns alunos. Os gráficos foram construídos a partir da dificuldade da questão que fica no eixo vertical e a ordem da questão respondida no eixo horizontal. Percebemos no gráfico de desempenho dos alunos que eles tendem a estabilizar em uma determinada dificuldade. Isso é evidente no aluno 38 , que não conseguiu superar a dificuldade 4, ficando numa dinâmica de acertar os problemas de dificuldade 3 e errar os seguintes. O mesmo comportamento é apresentado pelo aluno 25. Notamos também que o aluno 27 ficou oscilando entre a dificuldade 5 e 6, da mesma forma que o aluno 29, mas este conseguiu passar para um novo patamar entre 9 e 8.

Neste momento se vê bem o porquê de não utilizarmos médias, desviopadrão, análise de variâncias ou mesmo testes de fidedignidade: os alunos não respondem as mesmas questões e nem estão sob as mesmas condições. Cada caso deve ser avaliado, no entanto, podemos estudar a correlação que existe nos caminhos seguidos por alunos que possuem o mesmo desempenho. Utilizamos o conceito "trajetória na hipermídia" como a sequência de questões respondidas pelos alunos, assim como a página consultada durante a realização dos problemas.

Referente às consultas efetuadas vemos que a página referente ao conceito de velocidade média foi acessada 233 vezes, sendo então a mais consultada. A página referente às unidades foi acessada 212 vezes e a página com o exemplo de problema resolvido 179 vezes. A página referente à ajuda em matemática elementar foi acessada apenas 48 vezes o que nos faz questionar sua necessidade.

Vemos então que os alunos possuem a tendência de se estabelecer em um determinado nível de dificuldade. Dessa forma podemos pensar que se a hipermídia pudesse determinar estes níveis, poderia servir como um indicador de adaptação. No entanto, devemos pensar que tipo de indicador seria este, afinal, em algumas situações os alunos decaem de rendimento depois de se estabelecer no nível. Já outros, conseguem superá-lo, atingindo níveis de dificuldades crescentes antes de se acomodar novamente. Estes patamares refletem o momento em que o aluno não consegue resolver um problema. De acordo com a $C L T$, podemos afirmar que a quantidade de carga cognitiva relevante é insuficiente para que o aluno consiga realizar as operações necessárias na memória de curto prazo. Dessa forma, encontramos o ponto em que a quantidade de variáveis e conceitos, associados através de um enunciado que favorece a carga alheia, extrapola a capacidade do aluno. 
Figura 3: Gráficos de desempenho analítico de alguns alunos.

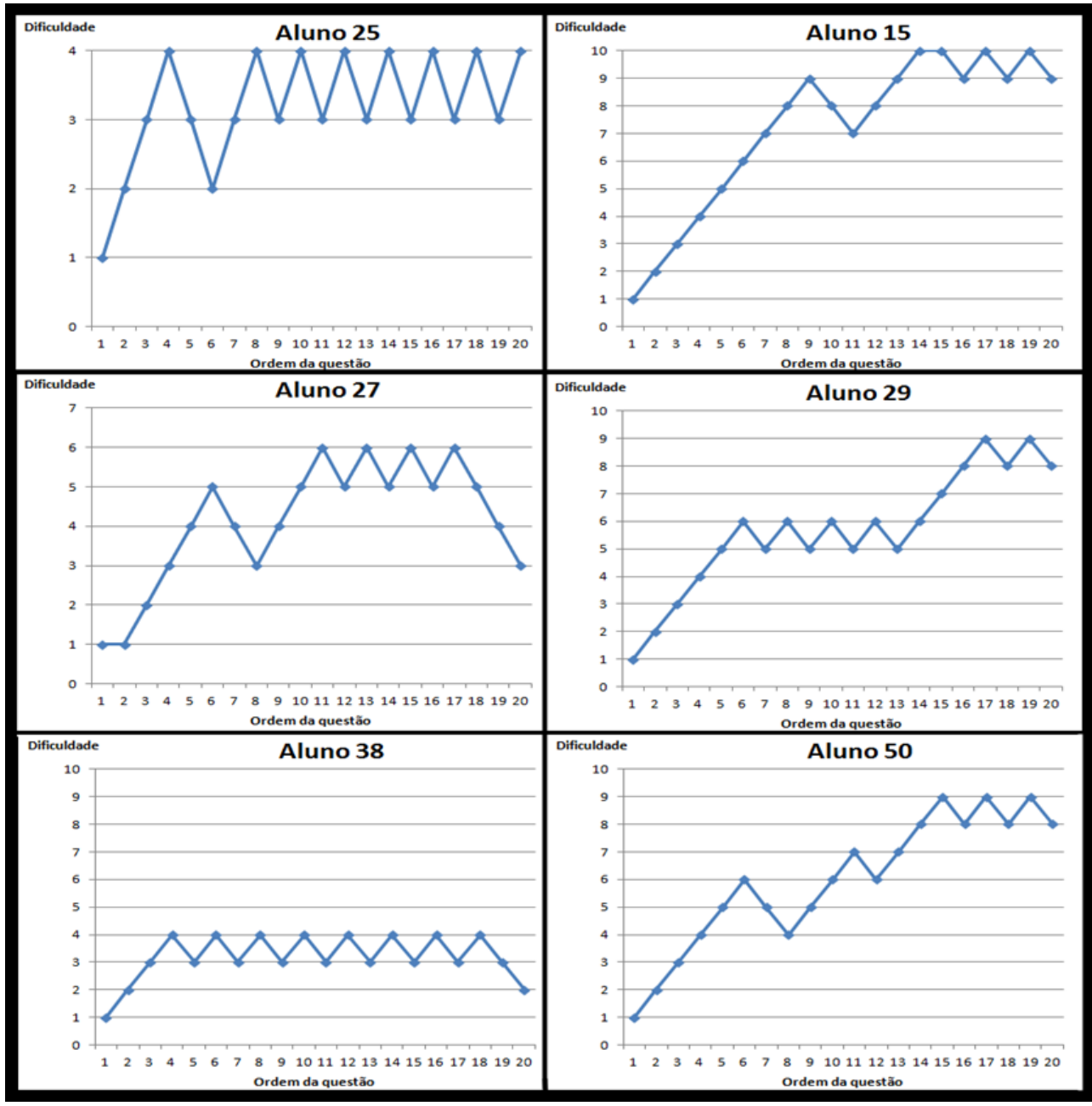

Como uma forma de atribuição de nota geral, vamos desenvolver uma equação que informe a nota de desempenho do aluno. Para isso vamos considerar a dificuldade alcançada pelo aluno, os acertos e erros, segundo a equação:

$$
\text { Nota }=\text { Dificuldade }+\frac{\text { Acertos }}{\text { Acertos }+ \text { Erros }}
$$

Nesta equação o termo dificuldade se refere ao nível final de dificuldade que o aluno atingiu e acertou. Assim, para que o aluno obtenha a nota máxima no teste é necessário que acerte todas as questões, mas se houver algum erro, sua nota deverá ser corrigida. Vamos fazer uma comparação dos desempenhos analíticos dos alunos que obtiveram notas iguais a 8,70.

Figura 4: Gráficos de desempenho analítico comparado dos alunos que obtiveram nota 8,70 . 


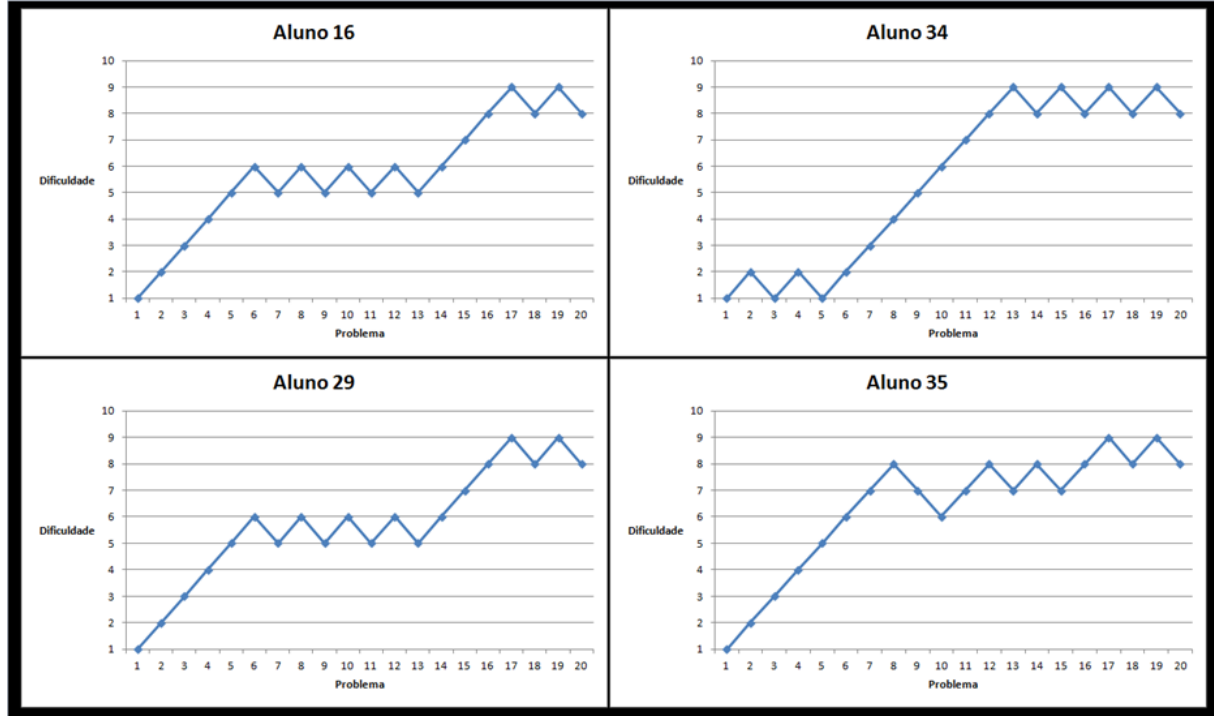

Notamos que nesses alunos existe a tendência em se estabelecer em determinado nível de dificuldade, mas não necessariamente o mesmo como pode ser visto na figura 4. Por essa razão, um indicador de adaptação baseado apenas no nível corrigido do aluno não parece adequado. Outra constatação é que desempenhos gerais iguais podem ter trajetórias parecidas na hipermídia, como foi o caso dos alunos 16 e 29. No entanto, parece mais comum que os alunos tenham suas trajetórias diferentes uns dos outros. Isto fica evidente olhando a tabela 5 onde consta a comparação das páginas consultadas por estes quatro alunos. Na tabela 6 encontra-se a mesma comparação entre alunos que obtiveram notas semelhantes próximos de 5,60.

Neste caso não foi possível constatar nenhum padrão, o que reforça a ideia de que cada aluno possui sua própria forma de articular um problema, com algumas similaridades. Vemos na tabela 6 que os alunos 24 e 28 tentam articular o conceito de velocidade média para resolver as questões, enquanto que o aluno 48 tenta através do exemplo resolvido. $\mathrm{O}$ aluno 53 tenta resolver os problemas envolvendo o conceito de velocidade média, o exemplo e as unidades em bloco.

Tabela 5: Comparação de páginas consultadas por alunos com nota 8,70.

\begin{tabular}{|c|c|c|c|c|}
\hline \multirow{2}{*}{ Aluno } & \multicolumn{4}{|c|}{ Página Consultada } \\
\cline { 2 - 5 } & $\begin{array}{c}\text { Velocidade } \\
\text { Média }\end{array}$ & Exemplo & Unidades & Aritmética \\
\hline 29 & 8 & 5 & 14 & 2 \\
\hline 16 & 7 & 5 & 2 & 1 \\
\hline 34 & 19 & 0 & 8 & 0 \\
\hline 35 & 5 & 4 & 4 & 2 \\
\hline
\end{tabular}

Tabela 6: Comparação de páginas consultadas por alunos com nota 5,60. 0 aluno 27 teve nota 5,55 e o aluno 28 teve nota 5,63. 


\begin{tabular}{|c|c|c|c|c|}
\hline \multirow{2}{*}{ Aluno } & \multicolumn{4}{|c|}{ Página Consultada } \\
\cline { 2 - 5 } & $\begin{array}{c}\text { Velocidade } \\
\text { Média }\end{array}$ & Exemplo & Unidades & Aritmética \\
\hline 20 & 7 & 3 & 9 & 1 \\
\hline 24 & 15 & 6 & 7 & 5 \\
\hline 27 & 6 & 3 & 3 & 1 \\
\hline 28 & 12 & 7 & 9 & 4 \\
\hline 46 & 8 & 4 & 6 & 0 \\
\hline 48 & 5 & 9 & 5 & 2 \\
\hline 53 & 11 & 10 & 8 & 1 \\
\hline
\end{tabular}

Disso poderíamos pensar em analisar as consultas realizadas por estes alunos durante o momento em eles estão estabelecidos em determinado nível. $\mathrm{O}$ aluno 16 durante sua estabilização momentânea nos níveis 5 e 6 não realizou nenhuma consulta. Enquanto que o aluno 29, que possui a mesma trajetória do aluno 16, consultou 4 vezes a página referente às unidades. Realizamos a mesma análise em alunos com notas semelhantes e foram constatadas as mesmas diferenças. Logo, concluímos que não existe padrão de consultas em alunos com notas iguais. Adaptar um conteúdo ao aluno através da apresentação de uma página específica não parece adequado em um primeiro momento. Os dados obtidos por esta hipermídia poderiam servir de modelo de usuário para um próximo módulo, a partir do qual o modelo seria atualizado e utilizado novamente em outro módulo seguinte. Este modelo deve ser individual, pois não foi possível constatar perfis semelhantes nesta abordagem.

\section{ANÁLISE DAS QUESTÕES}

Na tabela 7 vemos os dados referentes às questões utilizadas na hipermídia. $\mathrm{Na}$ coluna total de alunos que responderam às questões daquela dificuldade (TAR), vemos que o número de alunos respondentes diminui com o aumento da dificuldade, o que inicialmente pode indicar que a dificuldade atribuída às questões esteja correta, no entanto a coluna que mede o total de acertos pela quantidade total de tentativas (\% Acertos), que seria uma medida de dificuldade absoluta mostra-se totalmente irregular. Isto pode ser explicado por duas razões diferentes.

A primeira razão se deve à estabilização dos alunos em determinadas dificuldades como vimos anteriormente nas figuras 4 e 5 . Ou seja, quando isto acontece, eles contribuem mais para o aumento de tentativas de determinados problemas, aumentando tanto o número de acertos num nível de dificuldade e quanto o número de erros no nível imediatamente acima. Essa dinâmica é percebida entre as questões de dificuldade 1 e 2,3 e 4, 5 e 6 e em 8 e 9 . Isto na verdade significa regiões de estabilização, ou seja, regiões onde é mais provável que os alunos permaneçam. Não tomando este cuidado poderíamos nos enganar facilmente em pensar que os problemas de dificuldade 4 sejam mais difíceis que os de dificuldade 5 por exemplo. 
Tabela 7: Análise da consistência das dificuldades atribuídas a cada questão.

\begin{tabular}{ccccccr}
\hline $\begin{array}{c}\text { Dificuldade } \\
\text { da questão }\end{array}$ & Total & Corretas & Incorretas & $\begin{array}{c}\text { Total de Alunos que } \\
\text { Responderam } \\
\text { (TAR) }\end{array}$ & $\begin{array}{c}\% \\
\text { Acertos }\end{array}$ & Total / TAR \\
\hline 1 & 65 & 57 & 8 & 35 & 0,88 & 1,86 \\
\hline 2 & 62 & 41 & 21 & 35 & 0,66 & 1,77 \\
\hline 3 & 62 & 57 & 5 & 35 & 0,92 & 1,77 \\
\hline 4 & 72 & 49 & 23 & 35 & 0,68 & 2,06 \\
\hline 5 & 83 & 60 & 23 & 33 & 0,72 & 2,52 \\
\hline 6 & 97 & 31 & 66 & 33 & 0,32 & 2,94 \\
\hline 7 & 50 & 35 & 15 & 26 & 0,70 & 1,92 \\
\hline 8 & 68 & 53 & 15 & 24 & 0,78 & 2,83 \\
\hline 9 & 64 & 28 & 36 & 21 & 0,44 & 3,05 \\
\hline 10 & 35 & 16 & 19 & 10 & 0,46 & 3,50 \\
\hline
\end{tabular}

Mesmo assim é notória a quantidade de erros por tentativa que os alunos tiveram nos problemas de dificuldade 2 e 6 . Como pode ser visto na tabela 4, esses problemas exigiam duas transformações de unidades em algum momento de sua resolução. Esses dados nos indicam que aparentemente transformações de unidades é uma tarefa mais difícil do que manipular a equação da velocidade média. Logo, o aumento da carga cognitiva alheia associada à mudança de unidade é maior do que esperávamos, ou seja, conceitualmente, a dificuldade imposta por este tipo de operação é maior do que se poderia pensá-la como apenas mais uma operação matemática. Isto nos faz pensar em que momento exigir uma transformação de unidade estaria de fato contribuindo para o aprendizado de Física ou o abandono da questão.

Com isso resolvemos criar um indicador mais confiável de dificuldade atribuída analisando o número total de tentativas por aluno em cada dificuldade, indicado na coluna Total/TAR. Podemos reparar que se não houvesse a flutuação causada pelos problemas de dificuldade 2 e 6 , teríamos de fato um aumento gradual conforme o esperado.

\section{ANÁLISE DO MATERIAL RECOLHIDO}

Quando os alunos estavam resolvendo as questões na hipermídia, foi solicitados que desenvolvessem seus cálculos à caneta em uma folha de caderno para ser recolhido ao final da aula. O objetivo era também analisar esse material em conjunto com os dados obtidos pela própria hipermídia, e com isso seria possível validar esses dados qualitativamente, complementando a análise e gerando novos dados para a nossa futura hipermídia.

A tabela 8 consta a resolução típica de dois tipos de aluno: aqueles que seguem a ordem de resolução do problema e aqueles que não seguem. Quando construímos a tabela 4 pensamos na dificuldade imposta pelo problema a partir de uma solução padrão. Essa solução leva em consideração o uso correto da equação da velocidade média, mesmo tendo que calcular outra variável, a manipulação da equação deve estar clara e em conformidade com o exposto nas páginas de ajuda. 
No entanto, uma questão que surge é que os alunos poderiam querer usar outras formas de resolução, tal como usar dispositivos alternativos decorados tal como mostrado no aluno 3 da tabela 8 , o que colocaria em dúvida padronizar a resolução dos problemas.

A situação de resolução do aluno 3 foi observado em apenas 2 alunos, sendo que a maioria dos alunos ( 24 dos 35 , próximo de $70 \%$ ) seguiram o padrão de resolução semelhante ao do aluno 1 . Assim, os dados nos indicam que, partindo do pressuposto de que cada aluno pode resolver um problema à sua maneira, a partir de uma situação de consulta ao material, fica caracterizado que existe a tendência dos alunos seguirem o modo padrão de resolução. $\mathrm{O}$ que nos faz aceitar a hipótese de atribuir a dificuldade a uma questão a partir de uma resolução padrão.

Um aspecto positivo que pode ser retirado do material é a opinião que os alunos manifestaram sobre a hipermídia. Segundo Moreira (2004) uma das condições fundamentais para a ocorrência da aprendizagem significativa é que o aluno demonstre uma disposição para relacionar de forma substantiva e nãoarbitrária o novo material. Com isso, não importa quão potencialmente significativo (AUSUBEL, NOVAK E HANESIAN, 1980) é o material desenvolvido se o aluno não tiver a motivação necessária para aprendê-lo. Se ele estiver disposto a apenas memorizar o conteúdo teremos uma aprendizagem mecânica. Partindo dessa premissa, vemos que o aspecto motivacional da hipermídia foi alcançado com sucesso como é destacado na tabela 9, em que temos as opiniões de alguns alunos. Um dado muito relevante do estudo exploratório é que todos os alunos aprovaram o uso da hipermídia, demonstrando entusiasmo e dedicação durante a realização das tarefas. 
Tabela 8: Resolução de problemas de 3 alunos que realizaram a atividade.
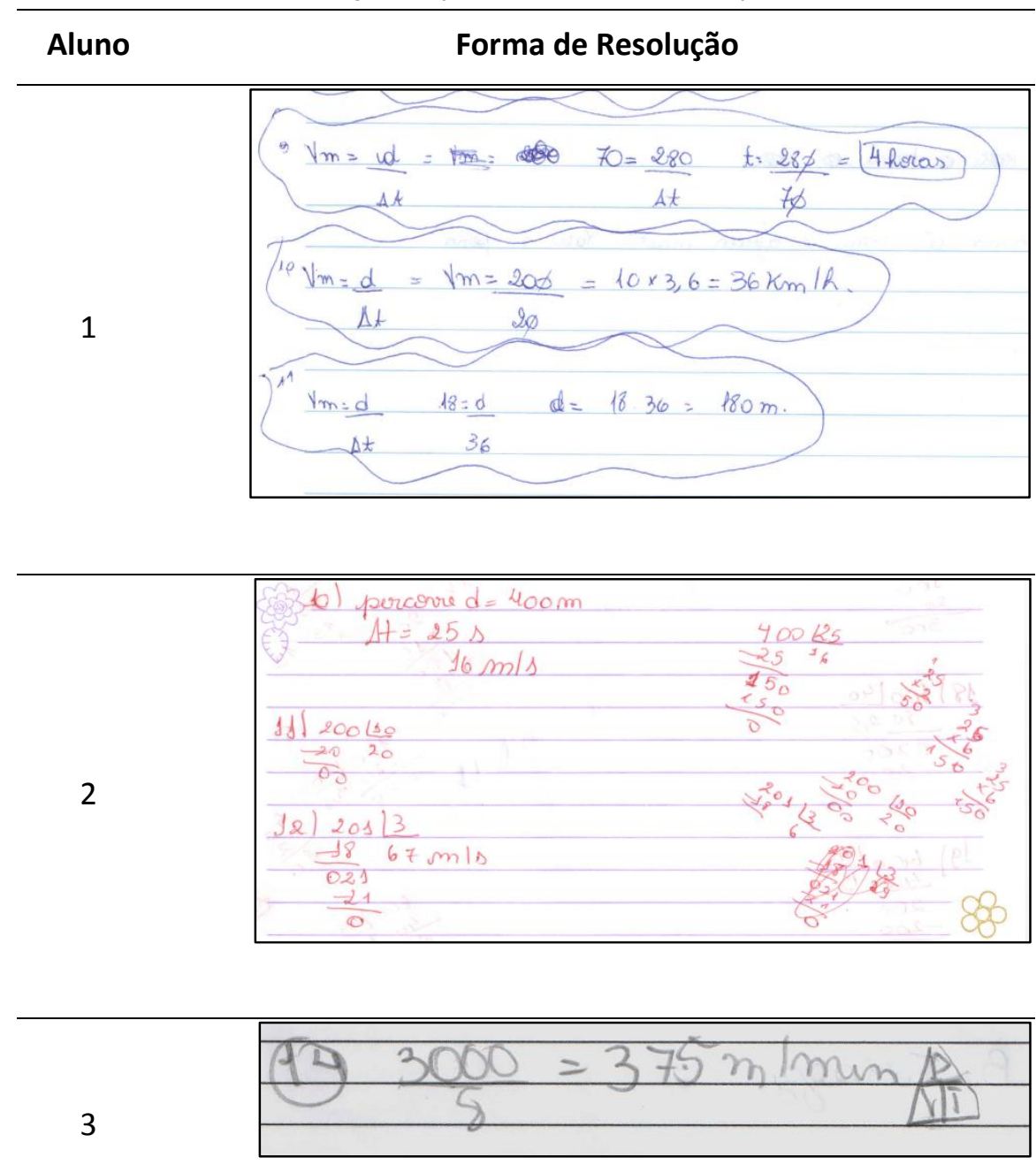

.




\section{Opinião do Aluno sobre a Hipermídia}

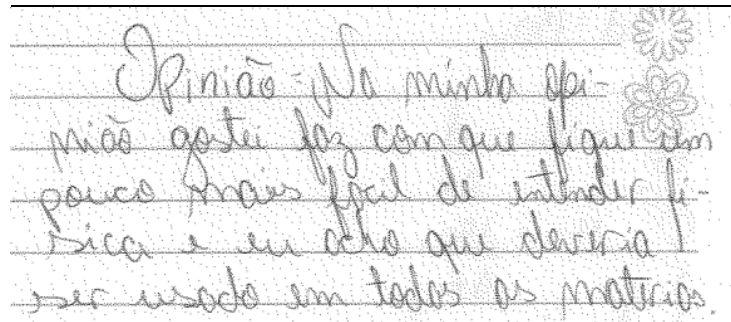

É un programe bom, que ajude os slunor ciom problemas re quem nä tem mueto dificuldade, por min esse programe vey en wer que we tento slgumas difículdades fors resolves alguins excucícion.

\section{Descrição}

Opinião: $\mathrm{Na}$ minha opinião gostei faz com que fique um pouco mais fácil de entender física e eu acho que deveria ser usado em todas as matérias.

É um programa bom, que ajuda os alunos com problemas ou que não tem muita dificuldade por mim esse programa 'vez' eu ver que eu tenho algumas dificuldades para resolver alguns exercícios.

Aminfo opiniöo é ave for staw de bolo, pois alguns erfenticios são lem elalwarados e com un ograu de dificuldade bom. Yorte deste teste e ostaria de foner outros.

OPNiAO: Gostei muito desre mona idéia de oprenalizads, fois nós bocemos mois nos herquntos e hodemos consultar ofudo - quaquer momento. É eme borme muito interessant para psender novos conteúdos.
A minha opinião é que foi 'show de bola', pois alguns exercícios são bem elaborados e com um grau de dificuldade bom. Gostei deste teste e gostaria de fazer outros!!

Opinião: gostei muito dessa nova forma de aprendizado, pois nós focamos nas perguntas e podemos consultar ajuda a qualquer momento. É uma forma muito interessante para aprender novos 


\section{CONCLUSÃO}

Construímos uma hipermídia com problemas fechados e quantitativos de Física para analisar o comportamento de alunos diante de uma situação de ensino de Física. Os problemas foram categorizados em dificuldades de acordo com a nossa análise na teoria da carga cognitiva (CLT). O objetivo era avaliar a consistência técnica da hipermídia a partir dos resultados obtidos através de uma pesquisa exploratória, que pela sua natureza não comprovativa serviu para levantar novas hipóteses e refinar o material construído.

Muitas pesquisas exploratórias podem e devem ser realizadas, e não necessariamente da mesma forma que apresentamos neste trabalho. Quando o assunto é buscar novas formas de adaptação de um conteúdo utilizando hipermídias, parece não haver limites quanto ao teste de novas ideias e concepções, e todas elas são igualmente importantes para o desenvolvimento da pesquisa em ensino de Física.

Alguns resultados importantes foram observados:

1. A tendência dos alunos de se estabilizar em questões de determinado conteúdo;

2. Os alunos tendem a seguir o padrão de resolução estabelecido pelo material;

3. Alunos com a mesma nota final, em desempenho, possuem trajetórias diferentes dentro da hipermídia, impossibilitando criar perfis unificados;

4. Os critérios para o diagnóstico da dificuldade dos problemas se mostrou consistente, mas que precisa ser melhorado;

5. Problemas que envolvem transformação de unidades parecem apresentar uma dificuldade maior do que a manipulação da equação do conceito de velocidade média;

6. Impossibilidade de avaliar a fidedignidade dos problemas por métodos estatísticos;

7. Grande motivação apresentada pelos alunos;

Para um próximo estudo, com caráter comprovativo, a hipermídia construída deve passar por algumas reformulações importantes, tais como:

1. Validação do conteúdo e dos problemas;

2. Os enunciados dos problemas de cada dificuldade devem ser os mesmos, modificando o módulo das variáveis;

3. Reposicionar os problemas de dificuldade 2 e 6 , que se mostraram muito difíceis;

4. Reformular a tabela 3 para adequar a dificuldade maior imposta pela transformação das unidades;

5. Desenvolvimento de 2 hipermídias: uma para avaliar o perfil 
Por fim, verifica-se que a CLT é um bom referencial para estudarmos resolução de problemas em Física. Uma hipótese que levantamos para pesquisas futuras é a possibilidade de testar a ideia, da literatura em resolução de problemas, de que os problemas quantitativos não favorecem a geração de hipóteses (GIL-PEREZ 1992):

... o fio condutor seguido até aqui permite conceber que a inclusão dos dados no enunciado como ponto de partida, respondendo a concepções indutivistas, orienta a resolução através do manejo de determinadas magnitudes sem que ela responda a uma reflexão qualitativa, nem as subseqüentes hipóteses. Deste modo, ao resolver um problema, o aluno se vê obrigado a buscar aquelas equações que relacionem os dados e incógnitas proporcionados no enunciado, caindo assim em um puro operativismo.

O autor atribui a concepções indutivistas a prática de resolução de problemas essencialmente fechados, incentivando o uso de problemas abertos tal como um problema típico enfrentado por um cientista. Por essa razão vemos como uma ótima pergunta de pesquisa:

Será que os problemas fechados e quantitativos, dependendo da metodologia, podem estimular a geração de hipóteses? 


\title{
An exploratory study to assess the difficulty of problems in teaching physics using the theory of cognitive load with a hypermedia support
}

\begin{abstract}
In this paper an exploratory study on problem solving with a hypermedia support. Basically, hypermedia has problems classified into difficulties theoretically established by Cognitive Load Theory (CLT). The CLT emerges as one focused on technical and development of instructional materials that facilitate learning theory. The study was conducted on 35 students of the 1st year high school of the IFRS (Federal Institute of Rio Grande do Sul Campus Ibirubá), which had its navigation and recorded in a log responses, as well as material produced by them while performing the task. Regarding the allocation of difficulty prior to the problems, the results suggest that CLT was consistent. With the CLT is possible to identify what type of problem that students cannot solve. As this exploratory study, we seek to contribute to the raising of new research questions.
\end{abstract}

KEYWORDS: Problem solving. Cognitive load. Hypermedia.. 


\section{NOTAS}

1 Do inglês: extraneous; melhor tradução.

2 Do Inglês: germane; melhor tradução.

3

Adaptado

de

http://www.southalabama.edu/oll/mobile/theoryworkbook/cognitiveloadtheory .htm

4 Do inglês Browser.

5 Acrônimo de Hipertext Preprocessor

6 Abreviação para a expressão HyperText Markup Language

\section{REFERÊNCIAS}

ALFONSECA, E.; RODRÍGUEZ, P.; PÉREZ, D. An approach for automatic generation of adaptive hypermedia in education with multilingual knowledge discovery techniques.Computers \& Education, v. 49, p. 495-513, 2007.

ANDAROLO, G.; BELLOMONTE, L.; SPERANDEO-MINEO, R. M.A computer-based diagnostic tutor for average velocity. Computers.\&Education. v.17, n.3, pp. 227 233, 1991

ARTINO Jr, A. R. Cognitive load theory and the role of learner experience: an abbreviated review for educational practitioners. AACE Journal, v. 16, n. 4, p. 425$439,2008$.

AUSUBEL, D. P. The acquisition and retention of knowledge: a cognitive view. Dordrecht, NL: Kluwer Academic Publishers, 2000. 232 p.

AUSUBEL, D. P.; NOVAK, J. D.; HANESIAN, H. Psicologia Educacional. Rio de Janeiro, RJ: Editora Americana LTDA, 1980. 615 p.

BADDELEY, A. D. Is working memory still working? European Psycologist, v.7, n.2, p.85-07, 2002.

BRUSILOVSKY, P. Methods and Techniques of Adaptive Hypermedia.User Modeling and User-Adapted Interaction.Special issue on adaptive hypertext and hypermedia, Dordrcht, v. 6, n. 2-3, 1996.

Adaptive Educational Hypermedia: From generation to and Communication Technologies in Education, Athens, Greece, September 29 October 3, 2004, pp.19-33. 
BRUSILOVSKY, P.; PESIN, L. Adaptive navigation support in educational hypermedia: An evaluation of the ISIS-Tutor. Journal of Computing and Information Technology, v.6, n.1, p.27-38, 1998.

BUTELER, L.; COLEONI, E. El conocimiento físico intuitivo, la resolución de problemas em física y el lugar de las ecuaciones matemáticas. Investigações em Ensino de Ciências, Porto Alegre, v. 17, n. 2, p. 4355-452, 2012.

CABRAL DA COSTA, S. S. C.; MOREIRA, M. A. Resolução de Problemas II: propostas de metodologias didáticas. Investigações em Ensino de Ciências, Porto Alegre, v. 2, n.1, p. 5-26, 1997a.

Resolução de Problemas III: fatores que influenciam na resolução de problemas em sala de aula. Investigações em Ensino de Ciências, Porto Alegre, v. 2, n. 2, p. 65-104,1997b.

Resolução de Problemas I: diferenças entre novatos e especialistas. Investigações em Ensino de Ciências, Porto Alegre, v. 1, n. 2, p. 176-192, 1996.

CALCATERRA, A.; ANTONIETTI A.; UNDERWOOD, J. Cognitive Style, hypermedia navigation and learning. Computers \& Education, v.44, p. 441-457, 2005.

CALVI, L.; De BRA, P. A flexible hypertext courseware on the web based on a dynamic link structure. Interact with Computers, v.10, p. 143-154, 1998.

CHANG, Y.C.; KAO, W.Y.; CHU, C.P.; CHIU, C.H.A learning style classification mechanism for e-learning. Computers \& Education, v. 53, p. 273-285, 2009.

CHEN, S.A cognitive model for non-linear learning in hypermedia programmes. British Journal of Educacional technology, v. 33, n. 4, p. 449-460, 2002.

CHONG, T.S. Recent advances in cognitive load theory research: implications for instructional designers. Malaysian Online Journal of instructional Technology, v. 2, n. 3, p. 106-117, 2005.

DAMANDO, F. S.; GUEDES, L. G. R.; MARTINS, W.; RIBEIRO, L. Ferramenta Avaliativa Dinâmica a partir da Teoria de Resposta ao Item. In: I Encontro Regional em Modelagem e Análise Computacional de Sistemas, Goiânia, 2004. 
GIL-PEREZ, D., MARTINEZ-TORREGROSA, J., RAMIREZ, L., DUMAS-CARRÉ, A., GOFARD, M. \& CARVALHO, A.M.P. Questionando a didática de resolução de problemas: elaboração de um modelo alternativo. Caderno Catarinense de Ensino de Física, 9 (1): 7-19, 1992.

GIL, A. C. Métodos e técnicas de pesquisa social. São Paulo, SP: Atlas, 201 p.

HUANG, S.L.; YANG, C.W.Designing a semantic bliki system to support different types of knowledge and adaptive learning. Computers\&Education, v. 53, p. 701712, 2009.

KALYUGA, S. Schema Acquisition and Sources of Cognitive Load. In: PLASS, J. L.; MORENO, R.; BRÜNKEN, R. (Org(s).). Cognitive Load Theory. New York: Cambridge University Press, 2010. p.29-47.

KALYUGA, S.; CHANDLER, P.; SWELLER, J. Managing split-attention and redundancy in multimídia instruction. Applied cognitive Psycology, v. 13, p. 351371, 1999.

KELLY, D.; TANGNEY, B. Adapting to intelligence profile in anadaptive education system. Interact with Computers, v. 18, p. 385-409, 2006.

LEE, C. H. M.; CHENG Y. W.; RAI, S.; DEPICKERE, A. What affect student cognitive style in the development of hypermedia learning system? Computers \& Education, v.45, p. 1-19. 2005.

LILLEY, M.; BARKER, T.; BRITTON, C.The development and evaluation of a software prototype for computer-adaptive testing. Computers \& Education, v. 43, n. 9, p. 109-123, 2004.

LIN, C.B.; YOUNG, S. S.C.; CHAN, T.W.; CHEN, Y.H. Teaching-oriented adaptive Web-based environment for support practical teaching models: a case study of "school for all". Computers \& Education, v.44, p. 155-172, 2005.

LUCERO, I; CONCARI, S.; POZZO, R. El análisis cualitativo em laresolucion de problemas de física y su influencia em el aprendizaje significativo. Investigações em Ensino de Ciências, Porto Alegre, v. 11, n. 1, p. 85-96, 206. 
MACHADO, D. I.; SANTOS, P. L. V. A. C. Avaliação da Hipermídia no processo de ensino e aprendizagem da física: o Caso da Gravitação. Ciência \& Educação, v.10, n.1, p. 75-100, 2004

MAMPADI, F.; MOKOTEDI, P. A. Towards effective combination of prior knowledge and cognitive styles in adaptive educational hypermedia systems. International Journal of Emerging Technologies in Learning, v.7, n.3, p.11-18, 2012.

MARTINS, A. C., FARIA, L., VAZ DE CARVALHO, C., CARRAPATOSO, E. User Modeling in Adaptive Hypermedia Educational Systems. Educational Technology \& Society, v.11, n.1, 194-207, 2008.

MÁXIMO, A.; ALVARENGA, B. Física volume 1. São Paulo: Scipione, 2008. 400 p.

MILLER, G.A. The magical number seven, plus or minus two: Some limits on our capacity for processing information. Psychological Review, v. 63, p. 81-97, 1956.

MOREIRA, M. A. A teoria da aprendizagem significativa de Ausubel. In: Teorias de aprendizagem. São Paulo: EPU, 2004.

MORENO, R.; PARK, B. Cognitive Load Theory: Historical Development and Relation to Other Theories. In: PLASS, J. L.; MORENO, R.; BRÜNKEN, R. (Org(s).). Cognitive Load Theory. New York: Cambridge University Press, 2010. p. 181-202.

PALAZZO, L. A. M. Modelos Proativos para Hipermídia Adaptativa. 114 f. Tese (Doutorado) - Universidade Federal do Rio Grande do Sul, Porto Alegre.

PALAZZO, L. A. M. Sistemas de Hipermídia Adaptativa. Disponível em: <http://ia.ucpel.tche.br/ Ipalazzo/Aulas/IWS/m08/Recursos/hiperpdf.pdf>. Acesso em: 09 out. 2008.

PALOUCCI, R. The effects of cognitive style and knowledge structure on performance using a hypermedia learning system. Journal of Educational Multimedia and Hypermedia, v7, p. 123-150.1998.

PARANÁ, D. N. Física. São Paulo: Editora Ática, 2005. 400 p.

PAPANIKOLAU, K. A.; GRIGORIADOU, M.; MAGOULAS, G. D.; KORNILAKIS, H. Towards new forms of knowledge communication: the adaptive dimension of a web-based learning environment. Computers \& Education, v.39, p. 333-360, 2002. 
PEDUZZI, L. O. Q. Sobre a resolução de problemas no ensino da física. Caderno Catarinense de Ensino de Física, v.14, n. 3, p.229-253, 1997.

POLLOCK, E.; CHANDLER, P.; SWELLER, J. Assimilating complex information Learning and Instruction, 12, p. 61-86, 2002.

RETALIS, R.; PAPASALOUROS, A. Designing and Generating Educational Adaptive Hypermedia Applications. Educational Technology \& Society, v.8, n.3, p. 26-35, 2005.

REZENDE, F.; OSTERMANN, F. Ferraz, G. Ensino-aprendizagem de física no nível médio: o estado da arte da produção acadêmica no século XXI. Revista Brasileira de Ensino de Física, v. 31, n. 1, 1402-1402, 2009.

SAMPAIO, J. L.; CALÇADA, C. S. Física volume único. São Paulo: Atual, 2005. 472 p.

SOUZA, C. A.; BASTOS, F. P.; ANGOTTI, J. A. P. Resolução de problemas de física mediada por tecnologias. Caderno Brasileiro de Ensino de Física, v. 25, n. 2, p. 310-339, ago. 2008.

SWELLER, J. Cognitive Load during problem solving: effects on Learning. Cognitive Science, 12, p. 257-285, 1988.

SWELLER, J.; CHANDLER, P. Why some material is difficult to learn. Cognition and Instruction, v.12, n. 3, p. 185-233, 1994.

SWELLER, J. Cognitive Load Theory: Recent Theoretical Advances. In: PLASS, J. L.; MORENO, R.; BRÜNKEN, R. (Org(s).). Cognitive Load Theory. New York: Cambridge University Press, 2010. p.29-47.

TABATABAI, M., Investigation of decision making process: a hypermedia approach. Interacting with Computers, 9, p. 385-396, 1998.

TSENG, J. C.R.; CHU, H.C.; HWANG, G.J.; TSAI, C.C. Development of an adaptive learning system with two sources of personalization information. Computers \& Education, v.51, p. 776-786, 2008.

TRIVIÑOS, A. N. S. Introdução à pesquisa em ciências sociais: a pesquisa qualitativa em educação. São Paulo: SP: Atlas, 1987.175 p. 
WALSH, L. N.; HOWARD, R. G.; BOWE, B. Phenomenographic study of students' problem solving approaches in physics. Physical Review Special Topics - Physics Education Research, v. 3, 2007.

Recebido: 19 de out. de 2014

Aprovado: 20 de mar. de 2016

DOI: 10.3895/rbect.v9n1.2116

Como citar:

OLIVEIRA, A. M. M. DE; MOREIRA, M. A. Um estudo exploratório para avaliar a dificuldade de problemas em ensino de física utilizando a teoria da carga cognitiva com o auxílio de uma hipermídia. Revista Brasileira de Ensino de Ciência e Tecnologia, v. 9, n. 1, p. 26-61, jan./abr. 2016. Disponível em: <https://periodicos.utfpr.edu.br/rbect/article/view/2116>. Acesso em: xxx. Correspondência:

Ângelo Mozart Medeiros de Oliveira

Avenida Osvaldo Aranha, 540, Bairro Juventude da Enologia, Bento Gonçalves, Rio Grande do Sul. Marco Antonio Moreira

Av. Bento Gonçalves, 9500, Campus do Vale CEP 91501-970 - Porto Alegre, Rio Grande do Sul/RS. Direito autoral: Este artigo está licenciado sob os termos da Licença Creative Commons-Atribuição 4.0 Internacional.

\section{(c) (1)}

